\title{
Statistically significant minimum pollen count in Quaternary pollen analysis; the case of pollen-rich lake sediments
}

\author{
Morteza Djamali ${ }^{*, 1}$, Kevin Cilleros ${ }^{1}$ \\ Institut Méditerranéen de Biodiversité et d'Ecologie - IMBE (Aix Marseille Univ, Avignon Université, CNRS, IRD), Europôle de l'Arbois, 13545 Aix-en-Provence, France
}

\section{A R T I C L E I N F O}

Article history:

Received 24 October 2019

Received in revised form 27 November 2019

Accepted 28 December 2019

Available online 15 January 2020

Keywords:

Pollen count

Coefficient of reliability

Pearson correlation coefficient

Paleolimnology

Quaternary

Southwest Asia

\begin{abstract}
A B S T R A C T
The statistical reliability of a pollen count in representing the true composition of modern and fossil pollen assemblages depends on the minimum number of pollen grains counted. In palynological literature this number varies between $<150$ and $>1000$, but very few studies have probed the question using robust statistical approaches. Here, we use the Pearson-Brown Prophecy formula and apply it to different fossil pollen counts from two large lake systems in Iran to calculate the minimum terrestrial and total pollen count necessary to obtain a reliable representativity of pollen assemblages. Our results surprisingly show that a pollen count of $<150$ is sufficient to achieve a reliability of 0.90 with no additional significant information obtained when counting more pollen. If the upland vegetation reconstruction is important, then terrestrial pollen counts as low as 67 could be sufficient. It seems that the statistically significant pollen counts are site-specific and vary between different environments and even within the same type of environment. We suggest that this value should be calculated for each pollen site so that the pollen analysts can more efficiently manage their time when counting pollen slides.
\end{abstract}

\section{Introduction}

The statistical treatment of the significant minimum pollen count (MPC) required to characterize modern and fossil pollen assemblages dates back to the 1930s, when palynology was still a science in its infancy (Erdtman, 1931). The first statistical approach to calculate the MPC was published by Barkley (1934). By comparing pairs of equal pollen counts from peat samples of central Pennsylvania and using both "Pearson correlation coefficient" and "Spearman-Brown prophecy formula", he suggested that a 175 to 200 pollen count was sufficient to obtain a reliability of 0.9 . This MPC value was only marginally greater than the 150 count suggested by Erdtman (1931) for organic samples of peat bogs. A MPC of 200 pollen grains has also been suggested to be statistically sufficient in provenancing honey samples (Jones and Bryant, 2001). A more recent melissopalynological study by Lau et al. (2018) calculated the minimum count needed to analyze honey-bee pollen pellets. The investigation found that the same pollen count (200) yielded a representative assessment of predominant, secondary and minor pollen types. The effect of the MPC on the precision of pollen-based

\footnotetext{
* Corresponding author.

E-mail address: morteza.djamali@imbe.fr (M. Djamali).

${ }^{1}$ The authors contributed equally to this study.
}

quantitative climate reconstructions using modern analog technique (MAT) has also shown that a count of 150 on fossil samples is sufficient to achieve vegetation reconstructions with $\geq 90 \%$ accuracy (Lytle and Wahl, 2005).

Hence, based on the current literature, it seems that $150-200$ pollen grains are needed to obtain a robust estimation of the pollen assemblages produced by a given type of vegetation in palynological samples. However, most calculations of reliable MPC on fossil pollen samples have been undertaken on organic sediments from temperate humid regions of North America and Europe (Erdtman, 1931; Barkley, 1934; Lytle and Wahl, 2005).

To test the validity of the MPC of 200 grains for samples of totally different sedimentary nature, and in a totally different floristic and ecological context, we applied the statistical approach of Barkley (1934) to two late Holocene pollen-rich samples from two large saline/playa lake systems in Iran (Djamali et al., 2008a, 2009). Such archives are increasingly being used in Quaternary palynological investigations and provide very long lacustrine records (Luly, 1993, 1997; Davis, 1998; Bader, 2000; Djamali et al., 2008a) in which the temporal resolution of the records will be determined by the number of pollen grains counted per sample. Indeed, in semi-arid to arid regions of the world, saline lakes and playas constitute invaluable records for paleoenvironmental reconstructions (Krinsley, 1972; Luly, 1997). Some of these large terminal lake systems have accumulated sediments over millions of years and can yield 
vegetation and climate records over $10^{7}$ year time scale (Davis, 1998). Furthermore, in the salty sediments of these lake systems, the pollen preservation is often excellent and pollen concentration is high (Davis, 1998; Djamali et al., 2008a). Therefore, many well-preserved pollen are available for analysts to exploit these sedimentary archives. In order to define an efficient pollen counting strategy, it is thus important to know the minimum pollen count that gives a satisfactory representation of pollen composition of a sample, beyond which no significant information is obtained. This will possibly help to avoid misallocation of analytical efforts, particularly pertinent when studying long lacustrine sequences measuring up to hundreds of meters (Davis, 1998; Djamali et al., 2008a). The present study is thus aimed at calculating the minimum pollen count needed to have statistically valid pollen spectra for pollen-rich samples from large lake systems.

\section{Materials and methods}

\subsection{Study sites}

Samples $(\mathrm{n}=2)$ were examined from two large lake systems in Iran (Fig. 1). The first study sample derives from Lake Maharlou, a seasonal hypersaline to playa lake in southwestern Iran (Krinsley, 1972; Dumas and Mietton, 2003) (Fig. 1). This lake has a surface area of $\sim 200 \mathrm{~km}^{2}$ and a watershed area of $>3900 \mathrm{~km}^{2}$ (Dumas and Mietton, 2003) located within the floristically rich Irano-Anatolian biodiversity hotspot. The vegetation is dominated by montane steppes, scrub communities and open woodlands (Carle and Frey, 1977). A vast wetland zone is found on the northwest board of the lake. A Holocene pollen record from this lake has already been published and has revealed a high concentration and diversity of pollen grains (Djamali et al., 2009).
The second sample derives from Lake Urmia, a large permanent hypersaline lake in northwestern Iran (Kelts and Shahrabi, 1986). The lake basin hosts a very long sediment archive that might go back to $>600 \mathrm{ka}$ (Djamali et al., 2008a). Several published pollen diagrams from the lake have indicated that the sediments are rich in pollen concentration and diversity (Bottema, 1986; Djamali et al., 2008a). The high pollen diversity reflects the huge watershed area of the lake in NW Iran, covering about 52,000 $\mathrm{km}^{2}$ (Khazaei et al., 2019) also in the Irano-Anatolian biodiversity hotspot. The vegetation in the catchment area is mostly composed of montane steppes in the northern part of the catchment and scrub communities and open woodlands in the south (Zohary, 1973). Vast wetland systems are found in the fluvio-lacustrine environments of river mouths, particularly in northeastern and southern parts of the lake, acting as a major source of aquatic pollen (Djamali et al., 2008b).

\subsection{Pollen analysis}

Two pollen-rich samples of similar age were selected from Lake Maharlou and Lake Urmia. Published pollen diagrams from both lakes are found in Djamali et al. (2008a, 2009) and the pollen records and counts can be consulted on the European Pollen Database (EPD) at http://europeanpollendatabase.net/index.php. The main characteristics of the studied samples are summarized in Table 1. Samples were prepared using classic pollen extraction techniques (Moore et al., 1991) with one extra treatment in hot $\mathrm{HCl}$ to remove the residual microcrystals found after the first $\mathrm{HCl}-\mathrm{HF}$ treatment. For each sample, 20 slides were prepared and, for every slide, pollen identification and counting was continued until 50 terrestrial pollen grains were tallied. In total, about 1000 terrestrial pollen grains were counted per sample. By adding the excluded pollen grains (aquatic pollen and Amaranthaceae), the

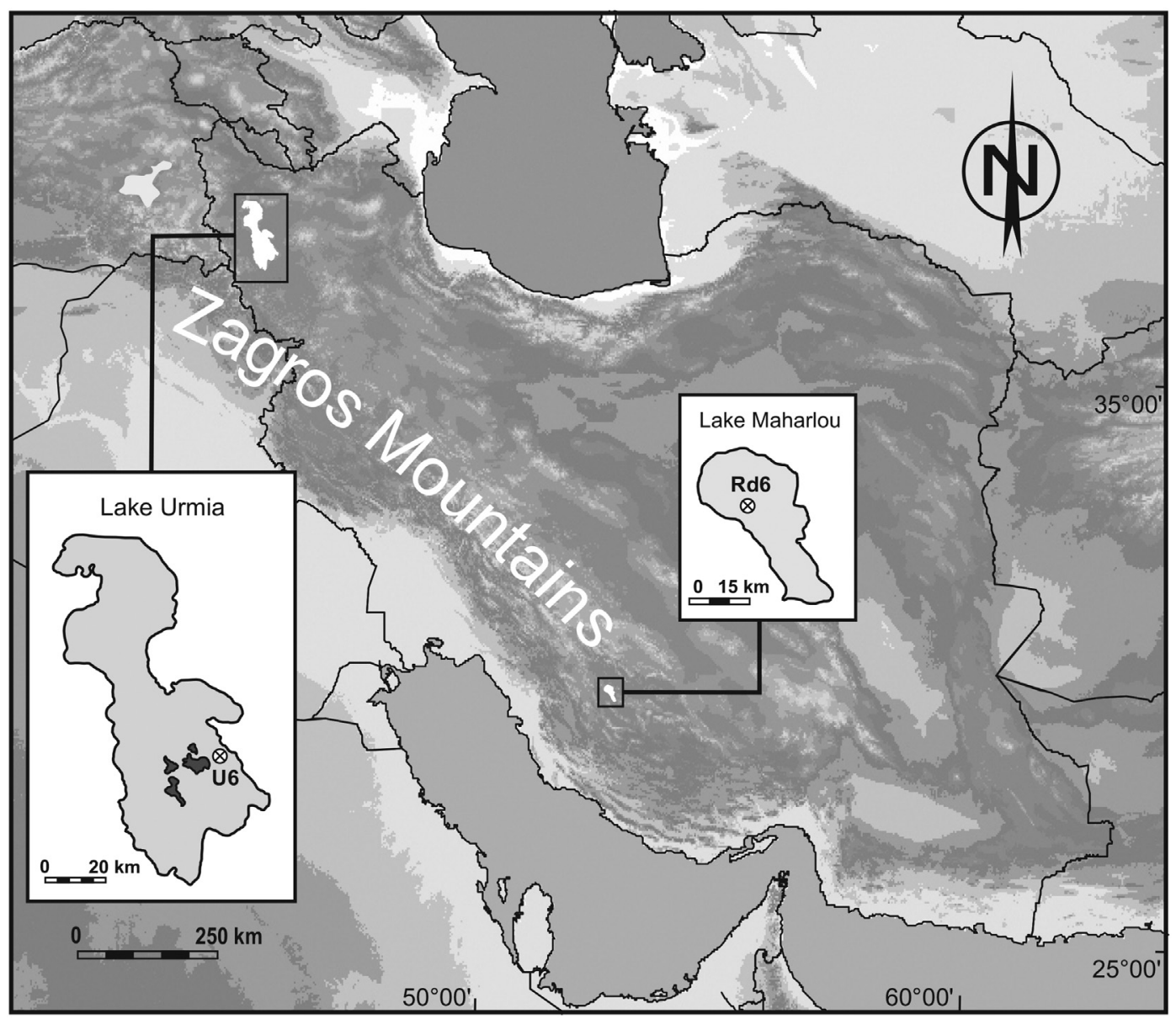

Fig. 1. Location map of sediment cores from Lake Urmia (U6) and Lake Maharlou (RD6) from which two pollen samples were studied. 
Table 1

Main characteristics of the two samples analyzed from Lake Urmia and Lake Maharlou.

\begin{tabular}{|c|c|c|c|c|c|c|}
\hline Sample code & Site & Core location & Depth $(\mathrm{cm})$ & Age (cal BP) & Lithology & Reference \\
\hline U6-1-10 & Lake Urmia & $\begin{array}{l}37^{\circ} 42^{\prime} 29^{\prime \prime} \mathrm{N} \\
45^{\circ} 26^{\prime} 02^{\prime \prime} \mathrm{E}\end{array}$ & $44-45$ & 2270 & Dark gray silt-clay with Artemia fecal pellets & Unpublished data \\
\hline RD6_91-92 & Lake Maharlou & $\begin{array}{l}29^{\circ} 28^{\prime} 28^{\prime \prime} \mathrm{N} \\
52^{\circ} 45^{\prime} 11^{\prime \prime} \mathrm{E}\end{array}$ & $91-92$ & 2100 & $\begin{array}{l}\text { Gray evaporitic-carbonate mud/minor } \\
\text { siliciclastic content }\end{array}$ & Djamali et al. (2009) \\
\hline
\end{tabular}

total pollen sum largely exceeded the 1000 count. Amaranthaceae were excluded from the terrestrial pollen sum because the halophilous chenopods dominate the saline soils surrounding the lakes (Djamali et al., 2008b; Djamali et al., 2009). The pollen concentration for each sample was then calculated based on the exotic spores of Lycopodium following Stockmarr (1971).

\subsection{Statistical analysis of pollen data}

For each sample, 20 tables were prepared. These contained the list of identified pollen taxa and their frequencies (counts). First, the Pearson correlation coefficient was calculated between (i) all data pairs (tables of $\sim 50$ counts): $\mathrm{r}_{\text {pairs }}$; and (ii) pairs of half the total counts in each sam-

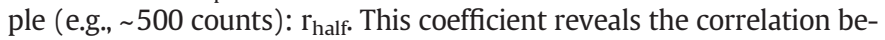
tween the smallest counts (50) and the largest split-half counts $(\sim 500)$. The Pearson correlation coefficient was calculated for tables containing (i) all terrestrial and aquatic/Amaranthaceae pollen and (ii) only terrestrial pollen to see if the estimated MPC shows any significant change when including or excluding the locally produced pollen of aquatic plants and Amaranthaceae. Second, following Barkley (1934), to test how the reliability of counts in representing the pollen spectra increases with greater counts, the Spearman-Brown prophecy or prediction formula (Brown, 1910; Remmers et al., 1927) was selected to calculate the coefficient of reliability of counts. The prophecy formula uses the observed correlation $\mathrm{r}_{\mathrm{obs}}$ between samples and links the expected correlation $r_{p}$ to the number of times $N$ the number of observations must be increased to obtain this correlation via $\mathrm{r}_{\mathrm{p}}=\left(\mathrm{N} \times \mathrm{r}_{\mathrm{obs}}\right) /$ $\left(1+r_{\mathrm{obs}}(\mathrm{N}-1)\right)$. This coefficient indicates how the reliability of a test increases when increasing the length of a test. In this case, the length of a test implies the count numbers. The coefficient will thus

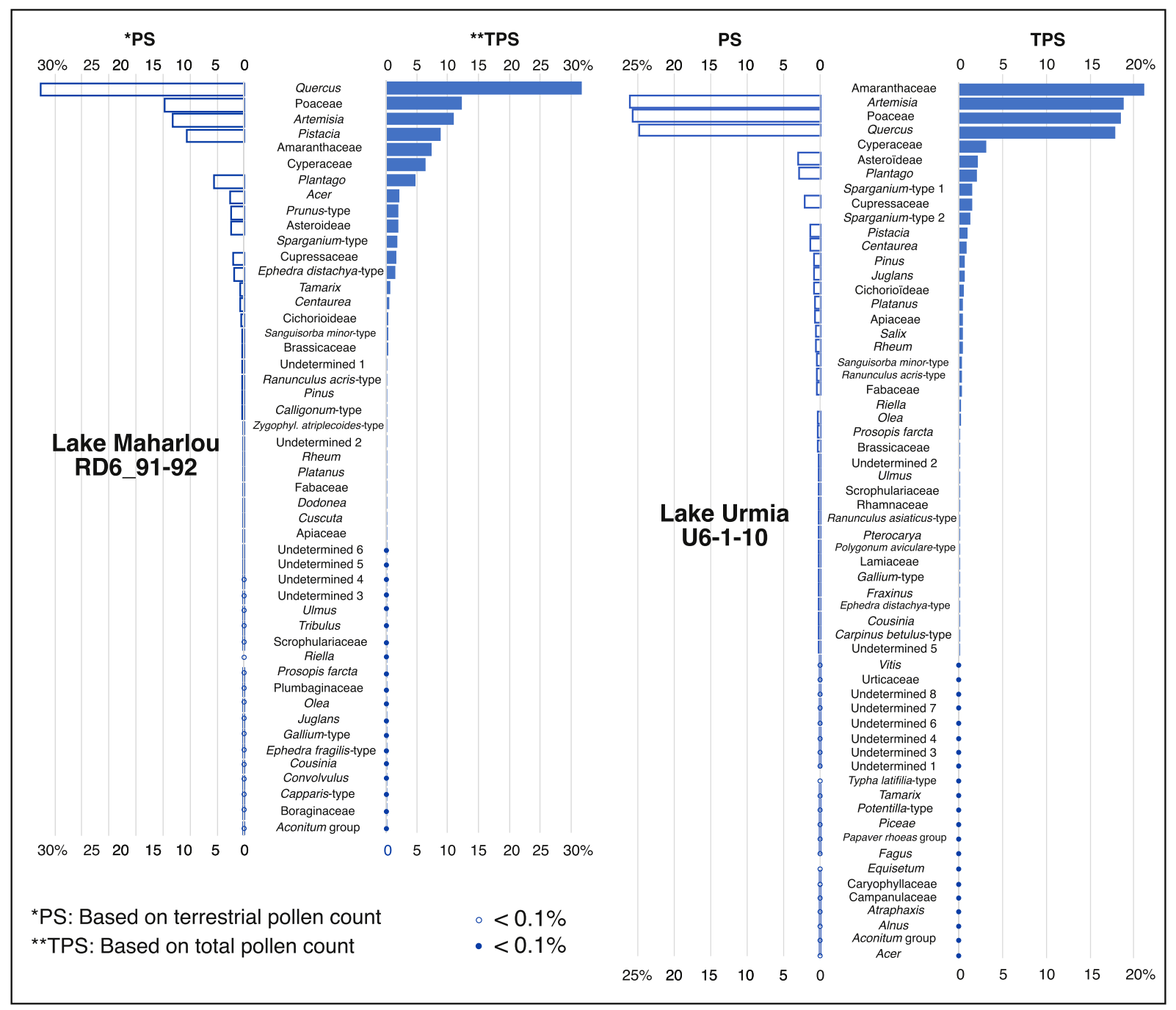

Fig. 2. Pollen percentages of two studied samples from Lake Maharlou (RD6_91-92) and Lake Urmia (U6-1-10). Both the total pollen sum (TPS) and the terrestrial pollen sum (PS) are represented. 
help to predict which count is needed in order to achieve a given correlation coefficient.

These analyses were performed using R 3.6.1 software (R Core Team, 2019). The script is provided in the Supplementary materials.

\section{Results}

\subsection{Pollen analysis}

In total, 51 and 64 pollen types were identified for samples from Lake Maharlou (RD6_91-92) and Lake Urmia (U6-1-10), respectively. Fig. 2 represents the pollen percentages of the major pollen taxa identified for two samples. The percentages were calculated for both the terrestrial Pollen Sum (PS: sum of terrestrial pollen) and the Total Pollen Sum (TPS: sum of terrestrial + aquatic + Amaranthaceae pollen). Five and four dominant pollen types account for $>75 \%$ of total pollen percentages in Lake Maharlou and Lake Urmia, respectively. The pollen concentrations were $21,934 \pm 344$ and $8005 \pm 594$ pollen/g of dry sediment for Lake Maharlou and Lake Urmia respectively.

\subsection{Statistical analysis}

The mean value for Pearson correlation coefficients calculated between all pairs of 50 pollen counts ( $r_{\text {pairs }}$ ) is high for both lakes (Fig. 3; Table 2). The mean values are $0.93 \pm 0.05$ for Lake Maharlou and $0.90 \pm 0.07$ for Lake Urmia when all taxa are included in the TPS. The Pearson correlation coefficients for half-split counts of 500 pollen $\left(r_{\text {half }}\right)$ are still higher with $0.99 \pm 0.003$ for Lake Maharlou and $0.99 \pm 0.001$ for Lake Urmia for counts on the basis of TPS (Table 2). Both $r_{\text {pairs }}$ and $r_{\text {half }}$ values for terrestrial counts are very close to those calculated on total pollen counts. A comparison of the Pearson intercorrelation coefficients in our lacustrine samples with those obtained for peat sediments by Barkley (1934) reveals a stronger correlation between the half-split counts $\left(\mathrm{r}_{\text {half }}\right)$ in the examined lacustrine sediments compared to those calculated for peat sediments ( 0.90 versus 0.88 ), even if the lacustrine counts are smaller (50 against 100 for peats).

Fig. 4 constitutes a graphic representation based on the SpearmanBrown prophecy or prediction formula on which the required pollen count (y-axis) to reach any given coefficient of reliability (x-axis) can be obtained by their intersection point along the solid curve, the socalled "frequency-correlation curve" following Barkley (1934). Accordingly, in the case of Lake Maharlou, the pollen counts of 286 and 136 total pollen counts are required to obtain coefficients of reliability of 0.95 and 0.90 , respectively (Fig. 4a). These values decrease to 226 and 107 for terrestrial pollen counts (Fig. 4b). At Lake Urmia, with a higher number of pollen types, lower counts of 174 and 83 are required to obtain the coefficients of reliability of 0.95 and 0.90 for total pollen counts (Fig. 4c). Finally, only 142 and 67 pollen counts are needed to obtain the same coefficients of reliability for terrestrial pollen.

At Lake Maharlou, beyond a coefficient of reliability of $0.9,150$ and 119 more pollen grains have to be counted to gain only 0.05 reliability for total pollen counts and terrestrial pollen counts, respectively. These values are 91 and 75 for the Lake Urmia sample. For both lakes, counting to 1000 pollen grains only adds $0.03-0.04$ in reliability. Thus, above a threshold of 0.90 , additional counts do not significantly increase the representativity of the pollen assemblages.

\section{Discussion}

The classic books on Quaternary pollen analysis suggest a wide range of pollen counts to obtain a reliable image of vegetation by surface and fossil pollen assemblages. Most suggest $>300$ pollen grains (e.g., Reille, 1990; Moore et al., 1991). However, the studies that have used statistical techniques have suggested MPC counts as low as 200 to achieve a (a)

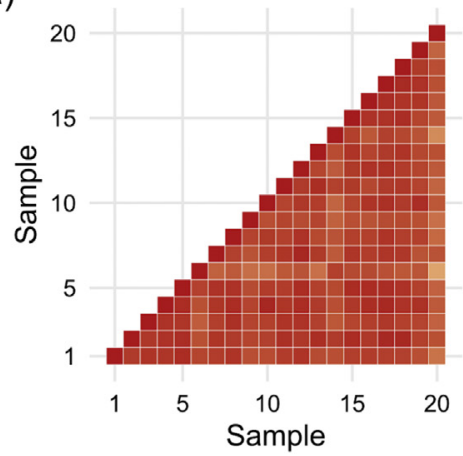

(c)

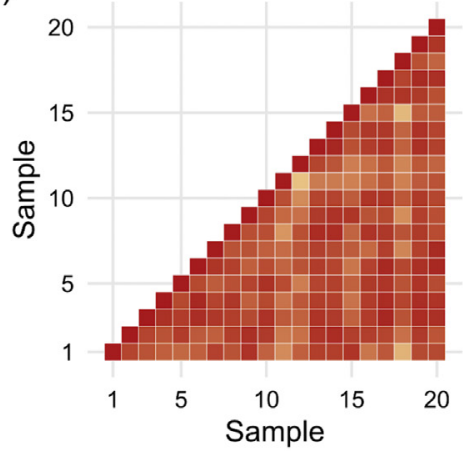

(b)

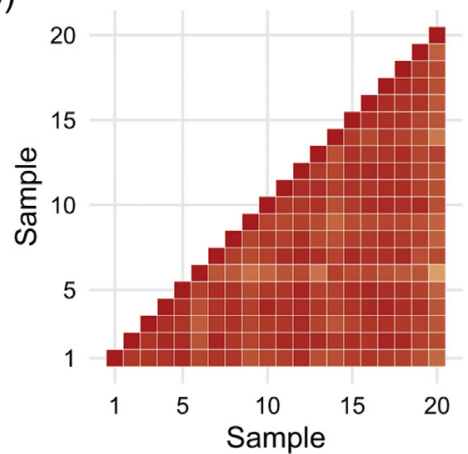

Pearson

Correlation

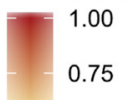

(d)

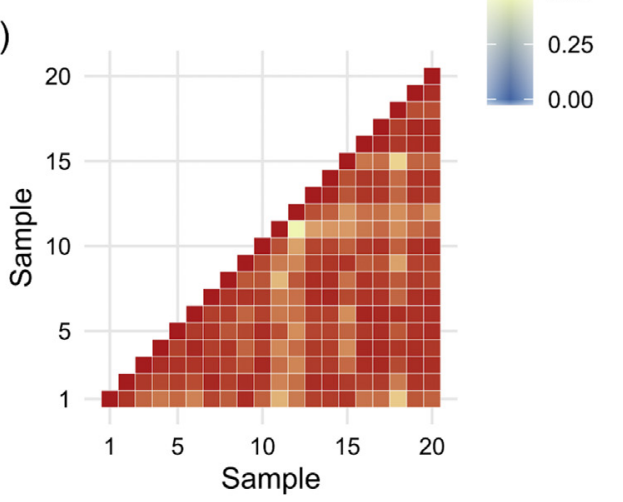


Table 2

Summary of the number of pollen grain types, Pearson correlation coefficient between all pairs of slide $\left(\mathrm{r}_{\text {pairs }}\right)$ and between halves of total count ( $\left.\mathrm{r}_{\text {half }}\right)$ and the count required to obtain a Pearson correlation value of 0.90 .

\begin{tabular}{|c|c|c|c|c|c|}
\hline & & $\begin{array}{l}\text { Number of } \\
\text { pollen types }\end{array}$ & $\begin{array}{l}\text { Mean Pearson correlation between } \\
\text { all pairs }\left(r_{\text {pairs }} \pm S D\right)\end{array}$ & $\begin{array}{l}\text { Mean Pearson correlation between } \\
\text { two split-halves }\left(r_{\text {half }} \pm S E\right)\end{array}$ & $\begin{array}{l}\text { Count required to obtain a Pearson } \\
\text { correlation of } 0.9\left(r_{p}=0.9\right)\end{array}$ \\
\hline \multirow[t]{2}{*}{ Lake Maharlou } & With aquatic & 51 & $0.92 \pm 0.04$ & $0.99 \pm 0.003$ & 136 \\
\hline & Without aquatic & 49 & $0.94 \pm 0.04$ & $0.99 \pm 0.003$ & 107 \\
\hline \multirow[t]{2}{*}{ Lake Urmia } & With aquatic & 64 & $0.89 \pm 0.06$ & $0.99 \pm 0.001$ & 83 \\
\hline & Without aquatic & 60 & $0.90 \pm 0.09$ & $0.99 \pm 0.002$ & 67 \\
\hline
\end{tabular}

good representation of the vegetation (Barkley, 1934; Lau et al., 2018). Our study shows that the pollen counts required to obtain a coefficient of reliability of 0.90 for two examined lacustrine samples are surprisingly lower than what is suggested in all previous publications. Our results suggest that, in the case of the pollen-rich sediments from the Iranian saline lakes, a MPC of 67-136 yields a reliability of 90\% and little or no significant increase in reliability is obtained by increasing the counts beyond this range. If the terrestrial (upland) vegetation reconstruction is the objective of a palynological study, then the counting of MPCs as low as 67 and 142 may be sufficient to obtain a reliability of 0.90 and 0.95 , respectively, as in the case of Lake Urmia (Fig. 4d). Such findings have important implications for Quaternary palynological studies in semi-arid and arid regions of the world where long lacustrine cores are increasingly being used in paleoenvironmental studies (Bader, 2000; Djamali et al., 2008a; Miebach et al., 2019). The temporal resolution of most of the available long pollen records from the saline lakes is relatively low due to the large number of samples needed to study. For instance, the sampling interval of the two 100 -m long pollen records of Lake Urmia presented in Djamali et al. (2008a) is $2 \mathrm{ka}$, which is insufficient to probe centennial-scale hydroclimatic variations. The resolution of another long pollen record from the Dead Sea also presents a low temporal resolution of $0.4 \mathrm{ka}$ (Miebach et al., 2019). Both of the above studies are based on a sum of $>500$ terrestrial pollen excluding pollen of aquatic plants (and Amaranthaceae in case of Lake Urmia). With a count of 150 pollen grains, three times the number of samples could be studied for the same investment of time, therefore allowing higher frequency hydroclimatic events to be investigated. In the case of the Urmia record, a MPC of 67 (Fig. 4d) implies that the pollen analyst could count seven times more slides.

It is still unclear why the outcome of the statistical test to calculate the MPC varies from site to site and yields higher values for peat bogs located in temperate regions (Barkley, 1934) than large lake basins in semi-arid regions (this study). The statistical approach used by Barkley (1934) and followed in the present study have not been applied to other environments and in diverse regions of the world. Furthermore, the test has not been applied to different time intervals with different (a)

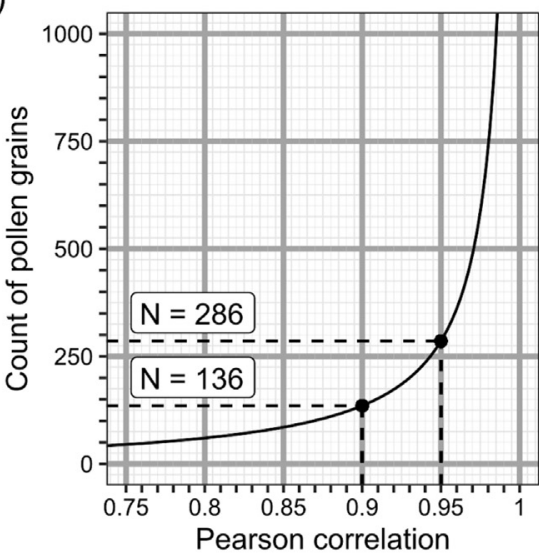

(c)

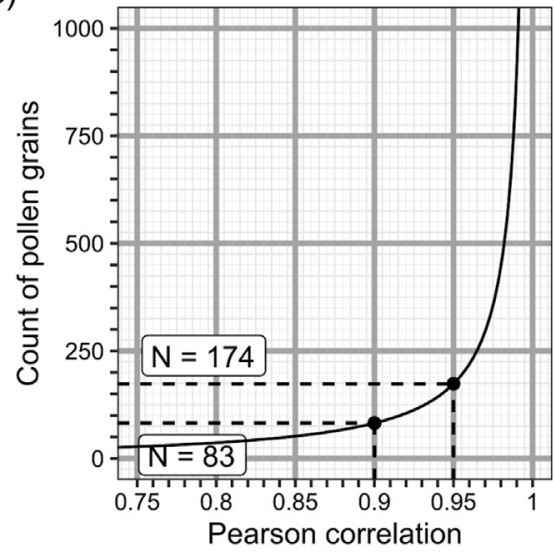

(b)

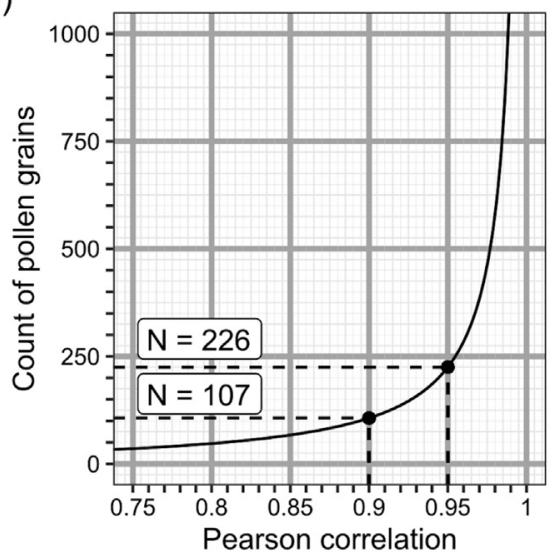

(d)

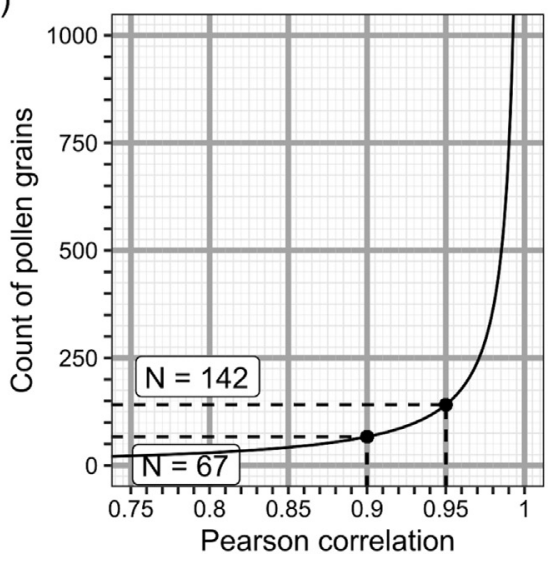

Fig. 4. Frequency-correlation curves showing the counts of pollen grains required to obtain various coefficients of reliability for Lake Maharlou (a,b) and Lake Urmia (c,d). Curves are obtained by using the Brown 'prophecy' form for all pollen counts, TPS ( $a, c)$ and for terrestrial pollen counts, PS (b,d). The count required to obtain Pearson correlation values of 0.90 and 0.95 are denoted with dashed lines and labeled. The solid curve can thus be used to obtain the number of counts required to achieve any given reliability. 
vegetation and hydroclimatic conditions for the same core sites. The statistically significant MPC may be a site-specific value depending on many factors, including the floristic composition and vegetation structure of the catchment, pollen transport and sedimentation hydrodynamics, physico-chemical properties of the wetland water and sediment, the taphonomic history of sediment and even the laboratory sample processing. We suggest that palynologists use a statistical approach to obtain the MPC for their study sites by choosing sediment representative of each lithological unit in their cores.

\section{Conclusions}

It is crucial to know the statistically significant MPC because it represents a trade-off between the degree of reliability of pollen counts in accurately representing vegetation and flora, and the pollen analysts time management. The latter is important when high resolution records are needed for long sediment cores. The MPC seems to be site-specific because the values are not the same between different environments and even within the same type of environment. It can be easily calculated using the methodology developed in the present paper, which is in turn based on Barkley (1934). The purpose of a palynological study is determinant in deciding which MPC to apply for pollen counts. When the reconstruction of main traits of vegetation based on dominant pollen types are the main objective of a study, an MPC with 0.90 reliability is sufficient to obtain a statistically significant representation of pollen assemblages. However, when the detailed floristic composition of vegetation and presence/absence of some rare species (e.g., under-represented cultivated taxa) is important, the counting should continue to higher reliabilities is obtained (e.g., 0.99 for countings of 1000 in the case of our study sites). In such cases, our approach could be complemented with other approaches such as accumulation curves.

\section{Data availability}

Pollen counts presented and analyzed in this study have been deposited in European Pollen Database (EPD, 2007-2019). The data are accessible through the website of EPD available at: http:// europeanpollendatabase.net/index.php.

\section{Declaration of Competing Interest}

None.

\section{Acknowledgement}

This project was supported by the CNRS-LIA funded project entitled "HAOMA" and ANR-DFG funded project "PALEOPERSEPOLIS". The second author's research was supported by Labex OT-Med (noANR-11LABX-0061) funded by the "Investissements d'Avenir", French Government project of the French National Research Agency (ANR) through the $A^{*}$ Midex project (noANR-11-IDEX-0001-02). Dr. Arash Sharifi (University of Miami) is thanked for providing a sample from core U6 of Lake Urmia. We are especially indebted to Dr. Nick Marriner for his thorough reading and for editing the English of the manuscript. We thank Michelle Leydet for storing our pollen data in EPD.

\section{Appendix A. Supplementary data}

Supplementary data to this article can be found online at https://doi. org/10.1016/j.revpalbo.2019.104156.

\section{References}

Bader, N.E., 2000. Pollen analysis of Death Valley sediments deposited between 166 and 114 ka. Palynology 24, 49-61.

Barkley, F.A., 1934. The statistical theory of pollen analysis. Ecology 15, 283-289.

Bottema, S., 1986. A late Quaternary pollen diagram from Lake Urmia (north-western Iran). Rev. Palaeobot. Palynol. 47, 241-261.

Brown, W., 1910. Some experimental results in the correlation of mental abilities. Br. J. Psychol. 3, 296-322.

Carle, R., Frey, W., 1977. Die Vegetation des Maharlu becken bei Shiraz (Iran) unter besonderer Berücksichtigung der Vegetation im Bereich der Süß- und Salzwasserquellen am Seeufer. Reichert, Wiesbaden.

Davis, O.K., 1998. Palynological evidence for vegetation cycles in a 1.5 million year pollen record from Great Salt Lake, Utah, USA. Palaeogeogr. Palaeoclimatol. Palaeoecol. 138, $175-185$.

Djamali, M., de Beaulieu, J.-L., Shah-Hosseini, M., Andrieu-Ponel, V., Amini, A., Akhani, H., Leroy, S.A.G., Stevens, L., Alizadeh, H., Ponel, P., Brewer, S., 2008a. A late Pleistocene long pollen record from Lake Urmia, NW Iran. Quat. Res. 69, 413-420.

Djamali, M., Kürschner, H., Akhani, H., de Beaulieu, J.-L., Amini, A., Andrieu-Ponel, V., Ponel, P., Stevens, L., 2008b. Palaeoecological significance of the spores of the liverwort Riella (Riellaceae) in a late Pleistocene long pollen record from the hypersaline Lake Urmia, NW Iran. Rev. Palaeobot. Palynol. 152, 66-73.

Djamali, M., de Beaulieu, J.-L., Miller, N.F, Andrieu-Ponel, V., Lak, R., Sadeddin, M., Akhani, H., Fazeli, H., 2009. Vegetation history of the SE section of Zagros Mountains during the last five millennia; a pollen record from the Maharlou Lake, Fars Province, Iran. Veg. Hist. Archaeobot. 18, 123-136.

Dumas, D., Mietton, M., 2003. Le fonctionnement hydroclimatique de la cuvette lacustre de Maharlou (Iran). Secheresse 14, 1-8.

EPD, 2007-2019. European Pollen Database. http://www.europeanpollendatabase.net/ index.php, Accessed date: 20 October 2019.

Erdtman, G., 1931. Pollen-statistics: A new research method in paleo-ecology. Science 73, 399-401.

Jones, G.D., Bryant, V., 2001. Is one drop enough? In: Goodman, D.K., Clarke, R.T. (Eds.), Proceedings of the IX International Palynological Congress, Houston, Texas, U.S.A., 1996. American Association of Stratigraphic Palynologists Foundation, pp. 115-120

Kelts, K., Shahrabi, M., 1986. Holocene sedimentology of hypersaline Lake Urmia, northwestern Iran. Palaeogeogr. Palaeoclimatol. Palaeoecol. 54, 105-130.

Khazaei, B., Khatami, S., Alemohammad, S.H., Rashidi, L., Wu, C., Madani, K., Kalantari, Z., Destouni, G., Aghakouchak, A., 2019. Climatic or regionally induced by humans? Tracing hydro-climatic and land-use changes to better understand the Lake Urmia tragedy. J. Hydrol. 569, 203-217.

Krinsley, D., 1972. The paleoclimatic significance of the Iranian playas. In: van Zinderen Bakker, E.M. (Ed.), Palaeoecology of Africa 6. A.A. Balkema, Cape Town, pp. 114-120

Lau, P., Bryant, V., Rangel, J., 2018. Determining the minimum number of pollen grains needed for accurate honey bee (Apis mellifera) colony pollen pellet analysis. Palynology $42,36-42$.

Luly, J.G., 1993. Holocene palaeoenvironments near Lake Tyrell, semi-arid northwestern Victoria, Australia. J. Biogeogr. 20, 587-598.

Luly, J.G., 1997. Modern pollen dynamics and surficial sedimentary processes at Lake Tyrell, semi-arid northwestern Victoria, Australia. Rev. Palaeobot. Palynol. 97 301-318.

Lytle, D.E., Wahl, E.R., 2005. Palaeoenvironmental reconstructions using the modern analogue technique: the effects of sample size and decision rules. The Holocene 15 , 554-566.

Miebach, A., Stolzenberger, S., Wacker, L., Hense, A., Litt, T., 2019. A new Dead Sea pollen record reveals the last glacial paleoenvironment of the southern Levant. Quat. Sci. Rev. 214, 98-116.

Moore, P.D., Webb, J.A., Collinson, M.E., 1991. Pollen Analysis. 2nd ed. Blackwell, Oxford.

R Core Team, 2019. R: A Language and Environment for Statistical Computing. R Foundation for Statistical Computing, Vienna, Austria https://www.R-project.org/.

Reille, M., 1990. Leçons de palynologie et d'analyse pollinique. Editions du Centre National de la Recherche Scientifique, Paris.

Remmers, H.H., Shock, N.W., Kelly, E.L., 1927. An experimental study of the validity of the Spearman-Brown formula as applied to the Purdue rating scale. J. Educ. Psychol. 18 187-195.

Stockmarr, J., 1971. Tablets with spores used in absolute pollen analysis. Pollen Spores 13. 615-621.

Zohary, M., 1973. Geobotanical Foundations of the Middle East. 2. Fischer, Stuttgart. 